\title{
A modelização como ferramenta complementar no ensino de Teoria da Comunicação
}

Luiz Marcelo Robalinho Ferraz

Doutor em Informação e Comunicação em Saúde pela Fiocruz, com estágio sanduíche pela Université Paris XIII. Professor substituto da Faculdade de Comunicação da Universidade Federal de Juiz de Fora (UFJF).

E-mail: marcelo.robalinho@gmail.com

Resumo: $O$ objetivo deste artigo é discutir a experiência de modelagem realizada na disciplina de Teoria da Comunicação ॥ dos cursos de Jornalismo e Rádio, TV e Internet da Universidade Federal de Juiz de Fora. Através da elaboração de uma escultura que refletisse a ideia de comunicação, a proposta da dinâmica foi fazer os alunos articularem a concepção criada com os conceitos da disciplina. Pensando no dialogismo no aspecto discursivo e na dimensão participativa e transformadora da prática comunicativa, a produção de um significado em comum buscou aproximá-los das teorias e dar-lhes condições para refletir criticamente sobre a importância do papel da comunicação.

Palavras-chave: comunicação; dialogismo; modelagem; relato de experiência; teoria da comunicação.
Abstract: This study aims to discuss the modeling experience realized in Communication Theory II discipline in Journalism and Radio, TV and Internet graduation courses of the Federal University of Juiz de Fora, Brazil. Through the elaboration of a sculpture that reflected the idea of communication, the dynamics proposal was to make students articulate the conception created with the theory learned in class. Thinking of dialogism in the discursive aspect and about the participative and transforming dimension of communicative practice, the production of a common meaning sought to bring them closer to theories and give them conditions to reflect critically on communicational role's significance.

Keywords: communication; dialogism; modeling; experience report; communication theory. 
comunicação \& educação • Ano XXIII • número 1 • jan/jun 2018

1. FERREIRA, Jorge Carlos Felz et al. Projeto político-pedagógico do curso de Jornalismo. Juiz de Fora: UFJF, 2015.

2. LOPES, Érika Savernini et al. Projeto pedagógico do curso de graduação em Rádio, TV e Internet (RTVI). Juiz de Fora: UFJF, jun. 2015.

3. BAKHTIN, Mikhail. Problemas da poética de Dostoiévski. 3. ed. Rio de Janeiro: Forense Universitária, 2002

4. FREIRE, Paulo. Extensão ou comunicação? 7 . ed. Rio de Janeiro: Paz e Terra, 1983.

5. ALMEIDA, lara Gilmony Farias et al. Utilização da massa de modelar como ferramenta para o processo de ensino-aprendizagem do conteúdo de divisão celular. In: CONGRESSO NACIONAL DE EDUCAÇÃO, 3., 2016, Natal. Anais... Natal, 2016, p. $1-7$.

6. KLAUBERG, Selma Derodea Weiss. O lúdico no ensino da Biologia: uso de um modelo didático para ensino da divisão celular mitótica. 2015. 21

f. Monografia (Especialização em Genética para Professores do Ensino Médio) - Universidade Federal do Paraná, Nova Londrina, 2016.

7. SPRINGER, Kalina Salaib; NUMMER, Andrea Valli. O uso de massinha de modelar para compreensão do relevo representado nos mapas físicos: proposta de prática para a geografia escolar. In: SIMPÓSIO NACIONAL DE GEOMORFOLOGIA, 6., 2006, Goiânia. Anais... Goiânia: UFG, 2006, p. 1-9.

\section{INTRODUÇÃO}

O uso de recursos didáticos representa ferramenta complementar no processo de ensino-aprendizagem como forma de fazer os alunos refletirem sobre os conceitos discutidos. Um deles é a modelização. A finalidade deste artigo é discutir a experiência realizada na disciplina de Teoria da Comunicação II dos cursos de Jornalismo e de Rádio, TV e Internet (RTVI) da Universidade Federal de Juiz de Fora, nos segundos semestres de 2016 e 2017. A atividade consistiu na construção de uma escultura que refletisse a ideia de comunicação e se tornasse ponto de partida para articulação dos conceitos trabalhados na disciplina. A dinâmica levou-os a interagir, facilitando a troca de ideias e proporcionando maior aproximação na discussão sobre comunicação. Possibilitou ainda a retomada das noções aprendidas na disciplina de Teoria da Comunicação I, o que ampliou o debate para as tendências abordadas em Teoria da Comunicação II. Em Jornalismo e RTVI, Teoria da Comunicação II integra os eixos curriculares de fundamentação contextual e teorias, e história da comunicação ${ }^{1,2}$.

Ao favorecer a concretização de uma representação simbólica que caracterizasse uma ideia comum, o trabalho buscou aliar prática à teoria do ponto de vista metodológico. O método fez os alunos pensarem criticamente sobre as próprias produções, identificando similaridades e diferenças entre elas, e em relação aos conceitos aprendidos. Pensando na comunicação como troca dialógica no aspecto discursivo ${ }^{3}$, e na dimensão participativa e transformadora da prática comunicativa $^{4}$, a elaboração de um significado comum buscou dar-lhes condições para refletir criticamente sobre a importância do papel da comunicação.

\section{OS USOS DA MODELAGEM EM SALA DE AULA}

O uso e as discussões em torno da importância da modelagem, também conhecida como arte tridimensional, vêm ocorrendo no âmbito da educação infantil e do ensino fundamental. Nessas duas fases da educação básica, os recursos lúdicos - tais como o desenho, a pintura, a colagem e a própria modelização - são mais comuns, utilizados para incentivar a ampliação do desenvolvimento cognitivo, afetivo e motor dos alunos por meio de diferentes linguagens presentes nas artes visuais. No ensino da Biologia e em disciplinas como Geografia e Matemática, ferramentas didáticas semelhantes vêm sendo usadas para ajudar estudantes no entendimento e na visualização de noções teóricas abstratas para ampliar as possibilidades do conhecimento a partir do momento em que interagem entre si para colocar a "mão na massa" e poder materializar os conceitos estudados ${ }^{5,6,7}$.

A modelização vem sendo adotada também como ferramenta complementar de alguns cursos de ensino superior, a exemplo de Medicina. Em cursos que trabalham com o modelo de aprendizado baseado em problemas, no qual o aluno se torna protagonista de seu processo "construindo seu conhecimento através do autoaprendizado ao longo das sessões tutoriais, com o suporte das 
aulas expositivas, das práticas laboratoriais, em unidades e programas de saúde coletiva e comunitária”, a atividade associa conteúdos que exigem imaginar assuntos, como a embriologia, tridimensionalmente (pela relação entre altura, largura e profundidade) para compreensão das anomalias. Experiência semelhante é realizada em cursos das ciências biológicas e da saúde, nos quais os alunos são instados a construir um modelo do sistema linfático humano com o uso de biscuit como ferramenta no estudo da anatomia ${ }^{9}$.

Nos cursos de Jornalismo e Rádio, TV e Internet, a modelização é uma possibilidade para articular a complexidade que envolve o conceito entre as perspectivas teóricas. Na disciplina de Teoria da Comunicação II, o panorama conceitual abarca desde significados produzidos pelo indivíduo na interação social, objeto do interacionismo simbólico ${ }^{10}$, passando pelo papel de receptor na comunicação, um dos focos de abordagem dos estudos culturais ${ }^{11}$, até as mudanças advindas com a cibercultura ${ }^{12}$. Possibilita ainda articular uma reflexão sobre os processos comunicacionais que surgem no trabalho em grupo, por envolver debates, conflitos, negociações, diálogos e afetos. Pretende-se trazer à tona a interlocução, tendo em vista diferenças entre os sujeitos, como também entre as produções realizadas pelos alunos.

Considerando a comunicação como diálogo entre sujeitos que buscam se expressar através do mesmo sistema de signos, a dinâmica tem a finalidade de construir com os estudantes um quadro comum a respeito da comunicação, inspirado nas ideias de Mikhail Bakhtin e Paulo Freire. A concepção bakhtiniana de dialogismo tem foco no discurso através das relações entre enunciados e revela a existência de vozes de outros discursos, condição de existência do Outro, pelo fato de eles não serem independentes, nem elaborados por um só sujeito. O diálogo é permanente e não se resume aos discursos existentes, mas também aos "discursos-respostas", que ainda não foram ditos, mas previstos no ato da enunciação, mesmo que inconscientemente. "Na realidade, toda palavra comporta duas faces. Ela é determinada tanto pelo fato de que procede de alguém, como pelo fato de que se dirige para alguém. Ela constitui justamente o produto da interação do locutor e do ouvinte"13.

Para Freire, a concepção dialógica está presente na comunicação entre indivíduos, em que o "nós" estabelece um "eu", já que o sujeito constrói sentidos sobre si e as coisas que o rodeiam no processo de troca com o outro. Nessa concepção, o saber é construído nas inter-relações. "A educação é comunicação, é diálogo, na medida em que não é a transferência de saber, mas um encontro de sujeitos interlocutores que buscam a significação dos significados"14. Em vez de depositar conteúdos no aluno, focando apenas na transmissão, a ideia é partir de sua realidade, "do que ele já conhece do valor pragmático das coisas e fatos de sua vida cotidiana, de suas situações existenciais. Respeitando o senso comum e dele partindo, Freire propõe a sua superação", comenta Gadotti ${ }^{15}$.

Refletir sobre o dialogismo enquanto discurso e prática comunicacional ajuda a pensar melhor nas conexões entre a dinâmica proposta e as teorias. É no âmago das diversidades surgidas que se pretendeu trabalhar as noções
8. SILVEIRA, Sheila Recepute; IDERIHA, Nilce Marzola. Uso de modelo tridimensional de argila no ensino-aprendizagem de embriologia humana. Mirabilia Medicinae, Barcelona, v. 1, p. 47-55, jul./ dez. 2013, p. 48.

9. SILVA, Augusta Antonia et al. O uso do biscuit como ferramenta complementar ao ensino de anatomia humana: um relato de extensão universitária. Revista Ciência em Extensão, São Paulo, v. 10, n. 2, p. 47-54, 2014.

10. BLUMER, Herbert. A natureza do interacionismo simbólico. In: MORTENSEN, David. Teoria da comunicação textos básicos. São Paulo: Mosaico, 1980, p. 119-137.

11. HALL, Stuart. Codificação/decodificação. In: Da diáspora identidades e mediações culturais. Belo Horizonte: Editora UFMG, Brasília, DF: Unesco, 2003, p. 387404.

12. LÉVY, Pierre. Cibercultura. São Paulo: Editora 34, 1999.

13. BAKHTIN, Mikhail. Marxismo e filosofia da linguagem: problemas fundamentais do método sociológico na ciência da linguagem. 6. ed. São Paulo: Hucitec, 1992, p. 113, grifo do autor.

14. FREIRE, Paulo, op cit., p. 46.

15. GADOTTI, Moacir (Org.). Paulo Freire: uma biobibliografia. São Paulo: Cortez; Instituto Paulo Freire; Brasília, DF: Unesco, 1996, p. 46. 
entrelaçadas ao debate sobre a comunicação aplicada à realidade dos alunos. A intenção foi incentivá-los a desenvolver a articulação entre teoria e prática, entendendo que ambas não podem estar apartadas, sobretudo em disciplinas de fundamentação contextual e teórica, como Teoria da Comunicação II.

\section{A PRÁTICA LEVANDO AO CONCEITO E AS TEORIAS FAZENDO REFLETIR A PRÁTICA}

A modelagem foi proposta como atividade de classe com grupos de cinco a seis integrantes para construção de uma escultura que represente a ideia de comunicação. O objetivo foi permitir que demonstrassem livremente o entendimento sobre comunicação, podendo recuperar ideias aprendidas em Teoria da Comunicação I, bem como incorporar noções discutidas em outras disciplinas, ainda sem promover discussão dos conteúdos de Teoria da Comunicação II, já que a atividade foi realizada no segundo dia de aula.

Para a elaboração da modelagem, foram fornecidas massas de modelar, cartolina, canetas coloridas, gizes de cera, palitos de picolé, canudos, revistas e jornais para recortes, barbante, tesoura, cola, fita adesiva e bola de isopor. Os grupos poderiam utilizar todos os itens ou apenas parte do material. O tempo estipulado para produção foi de, aproximadamente, uma hora e vinte minutos. Além disso, foi solicitado aos grupos que escrevessem um texto de um ou dois parágrafos sintetizando a ideia para complementar os sentidos sugeridos pela maquete.

A modelagem é usada nas séries iniciais com a função de trabalhar a motricidade e ampliar a criatividade, permitindo a livre expressão da criança através do incentivo ao desenvolvimento dessa habilidade ${ }^{16}$. Trazendo à tona a memória afetiva dessa atividade, que busca explorar o tato através da manipulação dos objetos, a dinâmica se tornou, em Teoria da Comunicação II, instigante para os estudantes e fonte preciosa de descobertas sobre as hipóteses deles acerca do que viria a ser trabalhado para o professor. A atividade foi inspirada em Cunha ${ }^{17}$, sobre os usos e o potencial que representa e pela interdisciplinaridade dos conteúdos sugeridos. Durante a dinâmica, perce-

16. SILVA, Elisangela Aparecida da et al. Fazendo arte para aprender: a importância das artes visuais no ato educativo. Pedagogia em ação, Belo Horizonte, v. 2, n. 2, p. 95-104, nov. 2010

17. CUNHA, Susana Rangel Vieira. Cor, som e movimento: a expressão plástica, musical e dramática no cotidiano da criança. Porto Alegre: Mediação, 1999. beu-se a interação entre as pessoas na finalização da modelagem e na escrita do texto. Destacamos a descrição de um dos grupos de Jornalismo. Neste artigo, cada grupo foi nomeado por uma letra para facilitar a identificação dos trabalhos abordados.

O trabalho começou com uma conversa em que decidimos qual caminho poderíamos tomar para criar a nossa escultura. Tivemos várias ideias boas e tentamos incluí-las em uma única realidade, que nos levou ao conceito e à estrutura da nossa obra. Sabendo então onde queríamos chegar e como poderíamos fazê-lo levando em conta o material que tínhamos à disposição, dividimos partes para a execução do projeto de acordo com as habilidades de cada integrante do grupo. (Grupo A, Jornalismo noturno) 
O grupo sintetizou todas as ideias dos integrantes, indicando o processo colaborativo. A interação também foi apontada nas dificuldades encontradas, como no Grupo B, de RTVI:

As maiores dificuldades que encontramos foram de aspecto técnico, uma vez que a estrutura que segurava parte da escultura cedia com facilidade, mas conseguimos contornar o problema trabalhando juntos e tomando muito cuidado. Foi muito prazeroso trabalharmos juntos porque não costumamos fazer trabalhos no mesmo grupo e foi uma oportunidade muito interessante além do processo fluir com uma facilidade surpreendente. Ficamos muito satisfeitos com o resultado. (Grupo B, RTVI diurno)

O desafio impôs ao grupo uma união maior entre os integrantes para a resolução do problema, sem que isso fosse empecilho para que o processo fluísse de forma prazerosa e natural. Durante a produção, observou-se uma integração entre os grupos na troca de materiais nas ocasiões em que a dinâmica foi realizada. Isso permitiu ao professor trabalhar ideias associadas à comunicação, como interação, diálogo e interlocução. Ao final, os grupos compartilharam seus modelos, tiraram dúvidas e discutiram as semelhanças e diferenças entre as esculturas e as concepções envolvidas. O conteúdo do debate foi retomado em aulas posteriores para ilustrar assuntos da disciplina, assim como a escultura, ponto de partida para a realização de trabalhos que analisaram as teorias estudadas à luz da concepção proposta.

Comparando ambas as turmas, as esculturas produzidas se mostraram distintas, apesar de associarem noções em comum. A turma de Jornalismo apresentou maior diversidade de formatos visuais, como cubo, árvore, rosa dos ventos, pirâmide e asteroide, para relacionar-se às ideias de transmissão, conexão e circuito. Já a turma de RTVI trabalhou mais a representação da teia e da rede, aludindo à noção de compartilhamento e conexão. Selecionamos duas representações de cada turma para discutirmos os conteúdos.

\subsection{A árvore e a rosa dos ventos como metáforas da comunicação}

Na Figura 1, o Grupo C de Jornalismo construiu a chamada "árvore do conhecimento", trazendo a pergunta: "como você se conecta com o mundo?". O intuito foi representar os diferentes caminhos da informação. Para o grupo, "as ramificações possibilitam a diversidade e fluidez do conhecimento entre diversos pontos", bem como "representam um leque de possibilidades, temas e modos de atingir o espectador, diferentemente do tronco, que indica um só caminho" (Grupo C, Jornalismo noturno). O circuito aparece uno e múltiplo, dando conta não só da diversidade de informações e temas tratados pela comunicação, como também permitindo conexão e fluxo permanentes, sendo o receptor o elo principal da cadeia. 


\section{comunicação \& educação • Ano XXIII • número 1 • jan/jun 2018}

Nos caminhos percorridos pela informação, as palavras-chaves são "transmissão", "conectividade", "globalização", "informação", "pessoas", "conhecimento", "fluxo" e "símbolos", complementados por "mudanças", "idiomas", "ensinar", "valores", "notícias", "aprender" e "união". No caule, aparecem letras soltas, que indicam os ruídos ocorridos no processo. Ganhando forma e sentido, as palavras definem o que é comunicação e a forma como o homem interage com o mundo. A ideia é que informação e conhecimento andam juntos e sustentam o mundo. "Os galhos, que carregam em si essas palavras, simbolizam as ramificações dos meios de comunicação e, mais ainda, simbolizam as infinitas possibilidades trazidas pela tecnologia com o passar dos anos" (Grupo C). No topo da árvore, aparece o globo terrestre cuja ideia é que "a comunicação sustenta o mundo e é responsável por fluxos, canais, possibilidades, fazendo parte também de seu processo histórico". Simbolizando pensamentos, ações e atitudes, dizem Gomes e Silva ${ }^{18}$ que a "árvore influencia a imaginação e permite a criação de metáforas como imagem do homem e de sua experiência enquanto eixo", sendo meio entre os mundos subterrâneos, da superfície e dos céus.

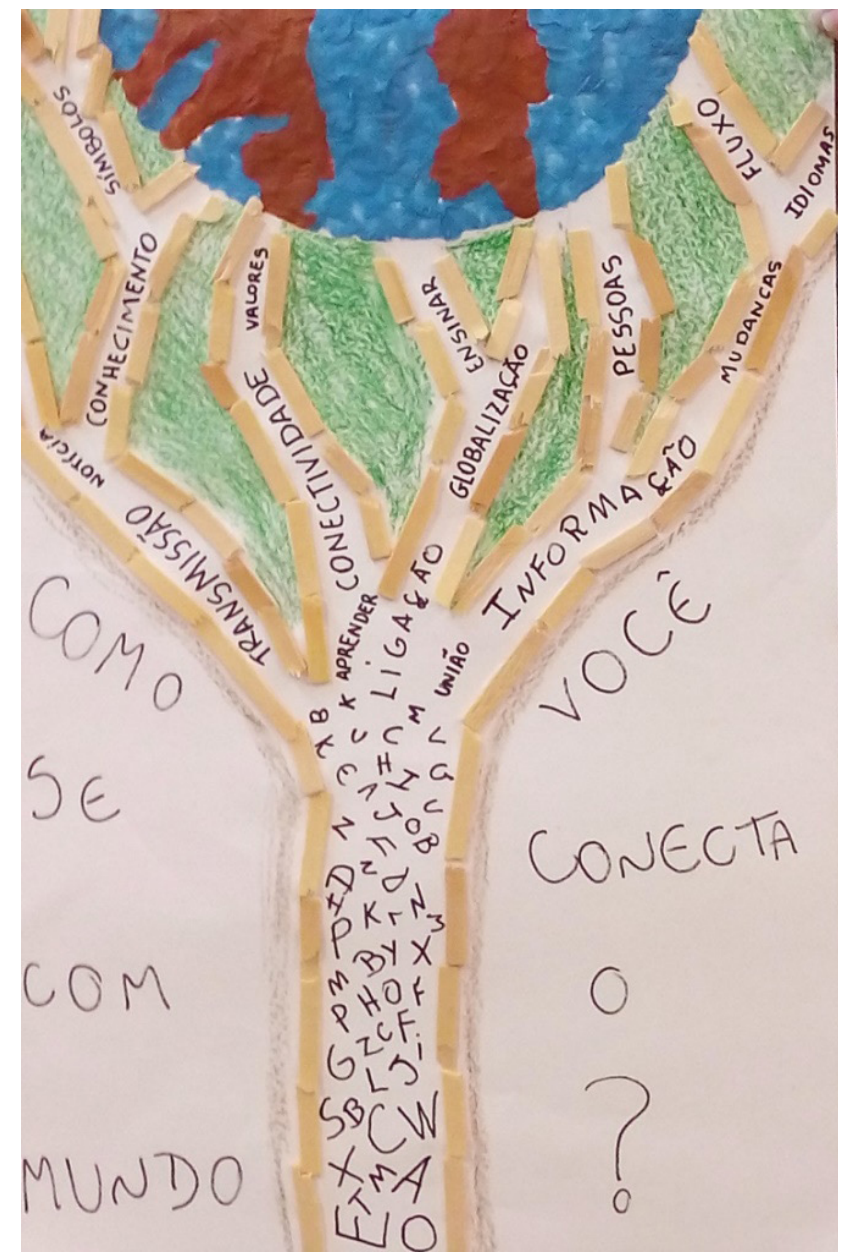

Figura 1: A árvore do conhecimento (Grupo C, Jornalismo noturno)

Fonte: Elaboração a partir da dinâmica realizada em sala. 
Já o Grupo D caracterizou a comunicação por uma rosa dos ventos (Figura 2). Usada pelos navegantes para guiá-los em direção ao conhecimento, a rosa dos ventos foi posta no centro do globo, fazendo "alusão à maneira como as teorias tentam entender a prática e explicar como isso se articula" (Grupo D, Jornalismo noturno). Há relação entre os pontos cardeais (Norte, Sul, Leste e Oeste) e os principais veículos (internet, televisão, jornais e impressos, e rádio), os pontos colaterais (Noroeste, Sudeste, Nordeste e Sudoeste) e os principais elementos contidos nesses meios (busca, teatro e entretenimento, ideias, publicidade e livros).

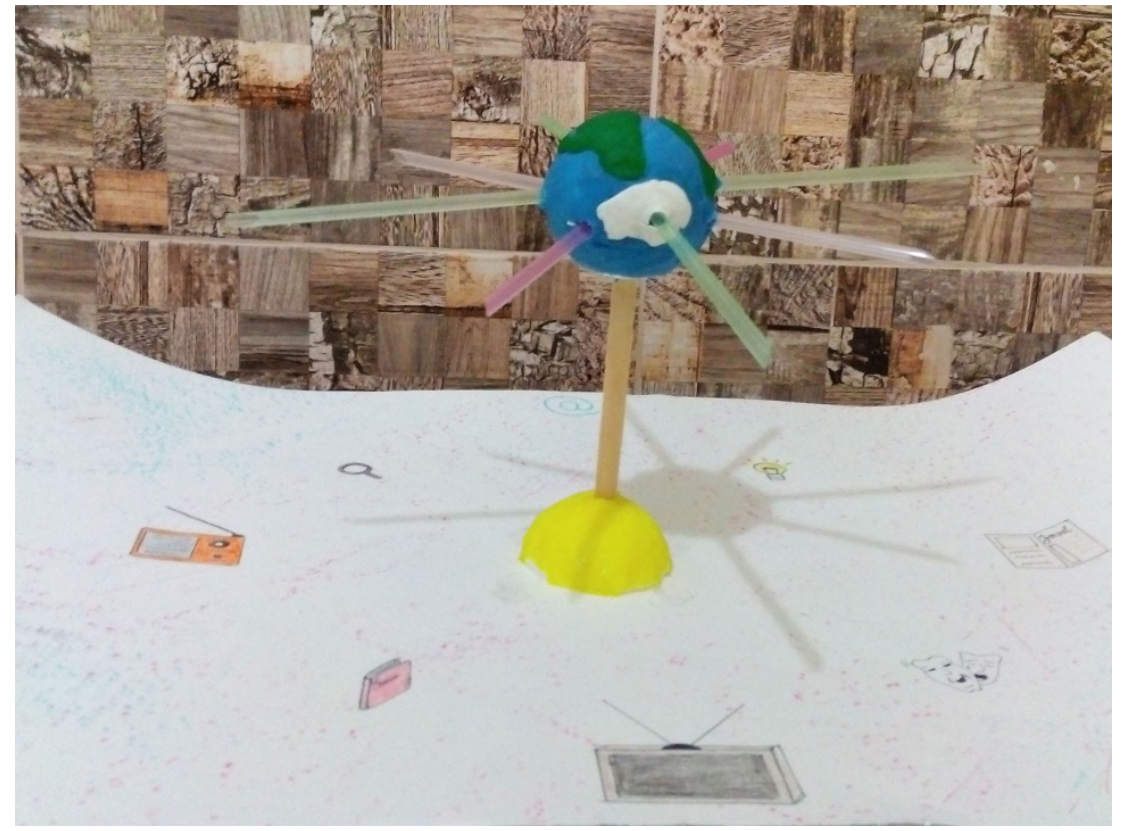

Figura 2: A rosa dos ventos da comunicação (Grupo D, Jornalismo noturno) Fonte: Elaboração a partir da dinâmica realizada em sala.

Além da procura por conhecimento e articulação entre teorias e práticas, a escultura indicou os sentidos de orientação ao "navegante" (os receptores), por intermédio da rosa dos ventos. Representando luz e sorte, ela pode significar um instrumento que indica o rumo certo e a decisão ponderada. Tendo os meios se convertido em fontes de informação e estudo na escultura, não é de se estranhar as alegorias dadas como pontos de referência para a localização sobre a superfície terrestre. Na concepção do grupo, as mídias se configuram em pontos que guiam o mundo, sendo capazes de afetar atitudes, costumes e relações da sociedade.

Ambas as representações visuais abordam a ideia de conexão. O Grupo $\mathrm{C}$ trata da "aldeia global" para associar a conexão e a interligação que os galhos teriam com a árvore e o globo terrestre. Criado por McLuhan ${ }^{19,20}$, o termo indica o encurtamento das distâncias provocado pelo advento das novas tecnologias eletrônicas e a interligação ocorrida, reduzindo o mundo a uma aldeia global.
19. MCLUHAN, Marshall. A galáxia de Gutenberg: a formação do homem tipográfico. São Paulo: Editora Nacional; Edusp, 1972.

20. Idem. Os meios de comunicação como extensões do homem (understanding media). 8. ed. São Paulo: Cultrix, 1996. 
$\mathrm{Na}$ árvore, "os galhos se conectam e interligam não só toda a árvore, mas também criam canal de conexão com o globo, assim como seria uma aldeia global" (Grupo C), assim como o caule e as ramificações sustentam um mundo globalizado e indicam como a globalização contribuiu para a disseminação dos signos através do mundo.

O Grupo D relaciona a rosa dos ventos à globalização, buscando expressar a forma como as pessoas estão se conectando umas com as outras. Dos cinco elementos de comunicação representados (academia, rádio, jornal, televisão e internet), o grupo destaca a maior influência da internet, ponto norte da escultura, indicando a apropriação desta com os demais, como se "unisse todos os outros pontos, permitindo, a partir de então, novas formas de comunicação" (Grupo D). Faz-se alusão à posição central da rosa dos ventos para conectar todos os eixos da estrutura e defende-se a ideia de uma comunicação interativa, mais livre e transparente, na qual o público possa interferir no processo, e o jornalismo, comprometido em informar os fatos, posicionado "de forma clara, fazendo com que o público saiba o que está sendo passado e qual é a visão de quem passa, evitando assim manipulações" (Grupo D, Jornalismo noturno).

\subsection{A rede e a teia como formas de representar a ideia de conexão}

No curso de RTVI, a ideia de conexão foi vista nas representações de rede e de teia, ambas construídas com a ajuda de barbantes, palitos de picolé e massas de modelar, sobretudo. No Grupo E, a comunicação foi retratada através de uma teia de compartilhamento de informação (Figura 3). O ponto de partida é a torre de transmissão, da qual saem várias informações (fios de barbante). Passando pelas pessoas (palitos presos com massa de modelar), os fios apontam o compartilhamento de informações, conhecimentos e histórias. As diferentes cores na base dos "bonecos" representam os interesses de cada pessoa, o grupo social a que pertencem, os gostos etc. "A ponta do fio, após passar por todas as 'pessoas', volta para a torre, como espécie de feedback", explicam (Grupo E).

A proposta é simbolizar "toda a informação, seja através da internet, livros, conversas, aulas, revistas, televisão entre outros” (Grupo E). Espécie de fonte, essa torre emanaria conteúdos que seriam recebidos pelas pessoas, dando origem a uma teia na qual ocorreria a troca de informações, saberes e ideias e faria o papel de unir a informação aos chamados "emanadores", denominando os mediadores no processo comunicacional. Essa noção remete a um fluxo de comunicação em dois níveis (two-step flow of communication), enfatizando o papel dos líderes de opinião na construção da opinião pública, a influência seletiva dos meios de comunicação e a dependência das relações interpessoais do receptor. 


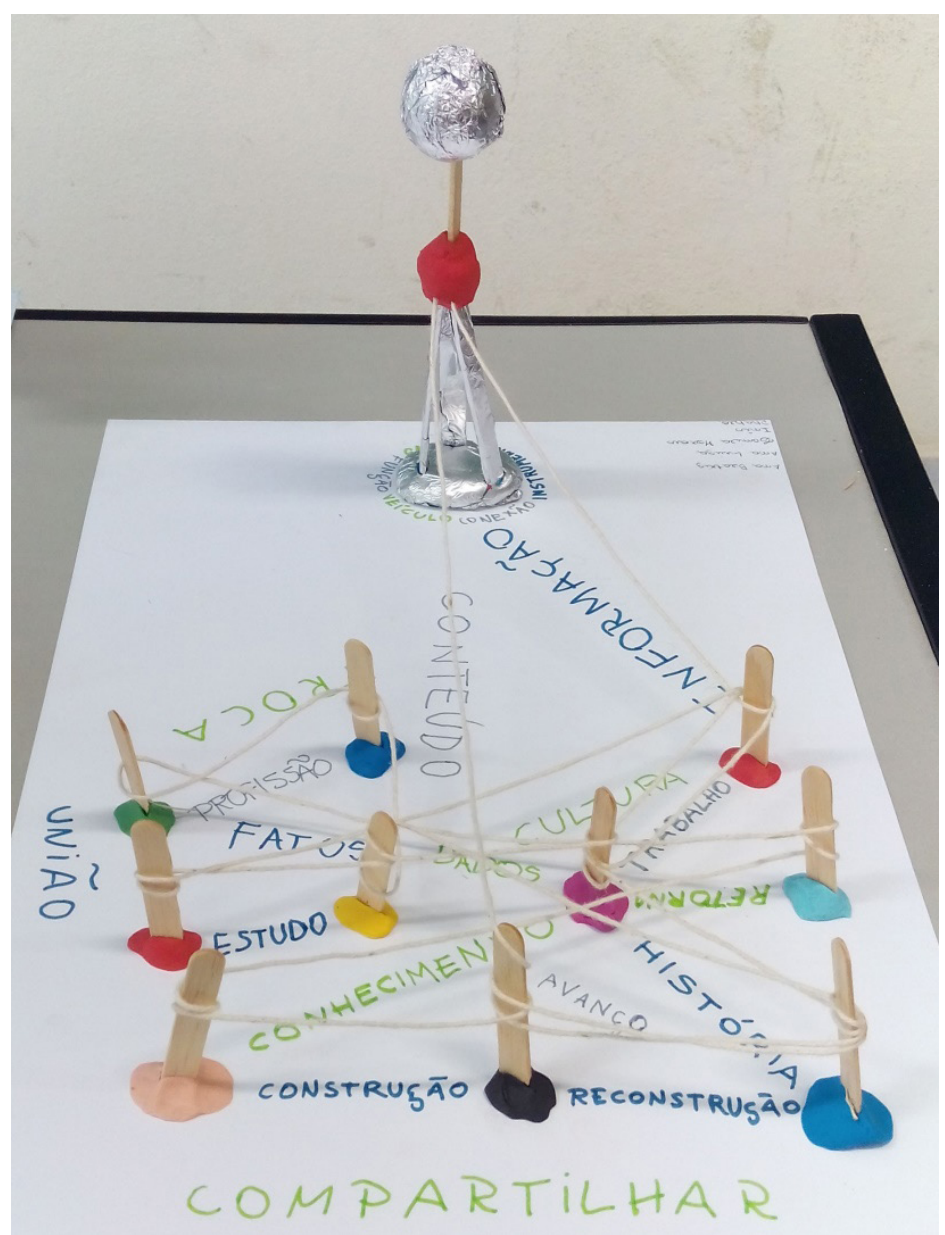

Figura 3: A teia de compartilhamento de informação (Grupo E, RTVI diurno)

Fonte: Elaboração a partir da dinâmica realizada em sala.

Para o Grupo E, a teia de compartilhamento é mais importante que o meio pelo qual a informação é difundida, ressaltando a troca de saberes. Na escultura, essa rede é conectada por pontos em que as palavras representam o que é a comunicação. Esses termos foram escritos em quatro dimensões, por sua vez divididas em grandes ("informação", "conteúdo", "troca” e "compartilhar"), médias ("união”, “fatos”, “cultura”, "dados”, "profissão”, “conhecimento”, "trabalho”, "história", "retorna” e "estudo”) e pequenas ("avanço", "construção" e "reconstrução"). Ao redor da torre, outras palavras foram escritas, numa dimensão ainda menor que a anterior ("função", "objetivos", "instrumento", “conexão" e "veículo").

As dimensões destacam as palavras, imprimindo certo sentido à concepção criada e revelando a relação estabelecida à pluralidade de noções que simboliza a comunicação. Observando a significação dos termos usados na modelagem, a concepção da teia enfatiza, numa dimensão maior, a mensagem, o significado, a partilha e a transformação. Em seguida, destacam-se o vínculo, a verdade, o conjunto de padrões de comportamento, de crenças, de conhecimentos e de costumes que distinguem um grupo social, a informação, a ocupação do 
sujeito, o empreendimento, o conjunto de conhecimentos relativos ao passado da humanidade e à sua evolução, o regresso e a análise. Num terceiro nível, ressalta-se a abertura de uma nova perspectiva para a solução de problemas, o trabalho de organização e criação de algo, e a reelaboração da criação. Já os significados que aparecem ao redor da torre são a atividade, o propósito, o recurso para atingir um resultado, a ligação e o transmissor.

Num outro plano de interpretação, associamos as palavras às três cores usadas para escreverem-nas (azul, verde e cinza). Segundo Heller ${ }^{21}$, o azul é geralmente a cor das características boas, podendo indicar tranquilidade, serenidade e harmonia. O verde representa esperança, saúde e vitalidade e simboliza a vida em seu sentido mais amplo. Já o cinza indica neutralidade, estabilidade e reflexão. Desse modo, "informação", "união", "fatos", "história", "estudo", "construção" e "reconstrução" imprimem sentido mais positivo (em azul) e indicam uma ideia de harmonia. Já os vocábulos "compartilhar", "troca", "cultura", "dados", "conhecimento" e "retorna" (em verde) apresentam simbologia mais próspera. A quantidade de palavras em cinza é menor (seis): "conteúdo", "profissão", "trabalho", "avanço", "função" e "conexão", o que configura neutralidade.

A interação entre receptores e mídias foi foco do Grupo F (Figura 4). Representando as pessoas, as bolinhas emitiriam informações, opiniões e sugestões (traços coloridos). "As cores variadas estão relacionadas tanto às formas de comunicação (gestos, fala, expressão corporal, facial etc.) quanto ao ponto de vista de cada pessoa" (Grupo F, RTVI diurno). No centro, estariam as mídias, comunicando-se com seu público e recebendo influência através dos barbantes, processo denominado de "retroalimentação".

Pela influência da mídia, algumas pessoas podem mudar suas opiniões ou enxergar um novo ponto de vista. Para exemplificar essa interação, misturamos as "cores da emissão", constituindo, assim, um pensamento diferente, emitido pelo próprio interlocutor anteriormente. (Grupo F, RTVI diurno)

21. HELLER, Eva. A psicologia das cores: como as cores afetam a emoção e a razão. Tradução Maria Lúcia Lopes da Silva. São Paulo: Gustavo Gili, 2013.

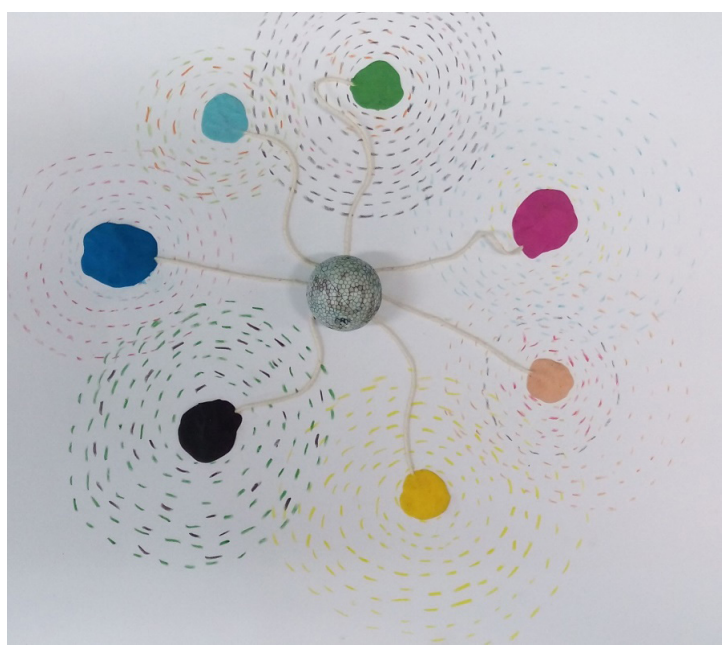

Figura 4: A retroalimentação entre receptores e mídias (Grupo F, RTVI diurno) Fonte: Elaboração a partir da dinâmica realizada em sala. 
Unindo pessoas às mídias, indica-se que estas transmitem mensagens, porém o público tem poder de interferir na agenda midiática, o que demonstra que a comunicação é uma via de mão dupla. As intersecções foram analisadas pela decodificação ${ }^{22}$, indicando maior liberdade na apreensão dos sentidos por parte dos receptores.

Pode-se perceber que em volta de cada bolinha de massinha criamos riscos de cores iguais que retratam o pensamento dessas pessoas, e além disso resolvemos pontilhar cores diferentes para destacar a interferência da informação passada entre as pessoas e também entre a mídia e o público. Observa-se também que esses pequenos traços que decidimos fazer se misturam uns com os outros, como uma interseção [...] para enfatizar que a comunicação está conectada e estamos a todo momento trocando informações uns com os outros. (Grupo F, RTVI diurno)

Outro aspecto na leitura dos alunos foi a diminuição do "poder absoluto" da mídia em relação aos receptores, mesmo que posicionada no centro. "Na verdade, buscou-se até demonstrar certa equidade, uma vez que, na contemporaneidade, qualquer um pode veicular informações e compartilhá-las na internet", defendem, apontando maior poder de interlocução por parte dos receptores. "Os traços coloridos em volta de cada indivíduo [...] sugerem os pensamentos que cada pessoa emite, contribuindo para pauta e opinião tanto da mídia quanto dos demais indivíduos que se relacionam direta ou indiretamente com eles" (Grupo F, RTVI diurno).

A diversidade de cores das massas de modelar usadas (azul-escuro, azul-claro, verde, violeta, rosa, amarelo e preto) e das linhas pontilhadas é um indicativo das ideias de diferença e individualidade presentes na concepção do Grupo F ao relacionar as reflexões de $\mathrm{Hall}^{23}$ sobre identidade cultural. Assim como o autor diz: "as identidades das pessoas na pós-modernidade não são perenes", o grupo buscou "uma variedade que sugere as diferentes posições do sujeito e as identidades que assumem”. Considerando ainda que as ideias das pessoas (pontilhados coloridos) se renovam na comunicação, formando novas percepções de mundo, as massas e os pontilhados representam a interação entre público e mídia, evidenciando "que a comunicação não é mais passiva, mas sim interativa" (Grupo F, RTVI diurno).

A noção de interação também aparece na teia de informação, assinalando o processo interativo na produção de significados entre indivíduos ${ }^{24}$.

A identidade é formada na interação da sociedade com o sujeito, pois ele não está isolado criando sua própria identidade. Então a partir da ideia do nosso trabalho podemos pensar que a rede de comunicação que fizemos tem a ver com isso. (Grupo E, RTVI diurno)

Atentando ao fato de o sujeito contemporâneo não ter identidade fixa, o grupo associa isso à globalização, referindo-se a "processos que integram e conectam comunidades em realidade e experiência, fazendo que o mundo seja interconectado". Mesmo distintas, as concepções avaliadas guardam proximidades, já que o encurtamento das distâncias, relacionado pelos grupos com o acesso
22. HALL, Stuart, op. cit. 2003

23. Idem. A identidade cultural na pós-modernidade. 12. ed. Rio de Janeiro: DPA, 2005.

24. BLUMER, Herbert, op. cit. 
à internet, propiciou transformações na comunicação. Para eles, isso tornou as pessoas mais empoderadas e provocou descentralização dos meios da posição hegemônica tradicional.

\section{ALGUMAS CONSIDERAÇÕES}

As análises representam um fragmento da riqueza das interpretações feitas pelos estudantes tendo como base a dinâmica de construção da escultura e a associação posterior feita com as teorias. A modelagem é um dos recursos didáticos que podem ser usados pelo professor a fim de possibilitar que o aluno demonstre o que sabe sobre comunicação e correlacione com o que aprendeu durante as exposições teóricas e os debates da disciplina.

Através de uma atividade lúdica que traz arte como elemento constitutivo, a modelagem permite maior identificação com os conteúdos e maior interação com colegas. Também auxilia nas discussões sobre o papel da comunicação, sobretudo no cenário de convergência dos meios na produção de conteúdos e na necessidade de se compreender as novas possibilidades de atuação do profissional. A participação ativa dos estudantes na produção dos modelos ajuda a trazer a abstração da comunicação para o nível mais concreto das ideias em uma disciplina como Teoria da Comunicação II. A materialização da concepção num modelo tridimensional permite que eles vivenciem, na prática, o processo comunicativo e sejam capazes de perceber como isso ocorre na associação com as noções teóricas abordadas.

Refletir sobre a coparticipação dos alunos para a elaboração de um significado em comum torna-se base para entender a importância do dialogismo na comunicação e no aspecto discursivo. A criação de uma representação visual revela as relações entre os discursos dos estudantes e destes com as teorias, denotando a interação viva e constante numa produção em conjunto. Na prática comunicativa, a dinâmica busca construir uma concepção conjunta, a partir da realidade dos alunos, indicando o caráter fundamental da troca, do diálogo e da participação para uma comunicação transformadora no processo educativo.

\section{REFERÊNCIAS BIBLIOGRÁFICAS}

ALMEIDA, Iara Gilmony Farias et al. Utilização da massa de modelar como ferramenta para o processo de ensino-aprendizagem do conteúdo de divisão celular. In: CONGRESSO NACIONAL DE EDUCAÇÃ̃O, 3., 2016, Natal. Anais... Natal, 2016. p. 1-7.

BAKHTIN, Mikhail. Marxismo e filosofia da linguagem: problemas fundamentais do método sociológico na ciência da linguagem. 6. ed. São Paulo: Hucitec, 1992. 
Problemas da poética de Dostoiévski. 3. ed. Rio de Janeiro: Forense Universitária, 2002.

BLUMER, Herbert. Anatureza dointeracionismosimbólico.In:MORTENSEN, David. Teoria da comunicação: textos básicos. São Paulo: Mosaico, 1980. p. 119-137.

CUNHA, Susana Rangel Vieira. Cor, som e movimento: a expressão plástica, musical e dramática no cotidiano da criança. Porto Alegre: Mediação, 1999.

FERREIRA, Jorge Carlos Felz et al. Projeto político-pedagógico do curso de Jornalismo. Juiz de Fora: UFJF, 2015.

FREIRE, Paulo. Extensão ou comunicação? 7. ed. Rio de Janeiro: Paz e Terra, 1983.

GADOTTI, Moacir (Org.). Paulo Freire: uma biobibliografia. São Paulo: Cortez; Instituto Paulo Freire; Brasília, DF: Unesco, 1996.

GOMES, Eunice Simões Lins; SILVA, Iêda Oliveira Caminha. Simbologia da árvore: uma análise das imagens míticas. Revista de Teologia e Ciências da Religião da Unicap, Recife, v. 1, n. 1, p. 205-218, 2011.

HALL, Stuart. Codificação/decodificação. In: __. Da diáspora: identidades e mediações culturais. Belo Horizonte: Editora UFMG; Brasília, DF: Unesco, 2003. p. 387-404.

A identidade cultural na pós-modernidade. 12. ed. Rio de Janeiro: DPA, 2005.

HELLER, Eva. A psicologia das cores: como as cores afetam a emoção e a razão. Tradução Maria Lúcia Lopes da Silva. São Paulo: Gustavo Gili, 2013.

KLAUBERG, Selma Derodea Weiss. O lúdico no ensino da Biologia: uso de um modelo didático para ensino da divisão celular mitótica. 2015. $21 \mathrm{f}$. Monografia (Especialização em Genética para Professores do Ensino Médio) - Universidade Federal do Paraná, Nova Londrina, 2016.

LÉVY, Pierre. Cibercultura. São Paulo: Editora 34, 1999.

LOPES, Érika Savernini et al. Projeto pedagógico do curso de graduação em Rádio, TV e Internet (RTVI). Juiz de Fora: UFJF, jun. 2015.

MCLUHAN, Marshall. A galáxia de Gutenberg: a formação do homem tipográfico. São Paulo: Editora Nacional; Edusp, 1972.

Os meios de comunicação como extensões do homem (understanding media). 8. ed. São Paulo: Cultrix, 1996.

SILVA, Augusta Antonia et al. O uso do biscuit como ferramenta complementar ao ensino de anatomia humana: um relato de extensão universitária. Revista Ciência em Extensão, São Paulo, v. 10, n. 2, p. 47-54, 2014. 
SILVA, Elisangela Aparecida da et al. Fazendo arte para aprender: a importância das artes visuais no ato educativo. Pedagogia em ação, Belo Horizonte, v. 2, n. 2, p. 95-104, nov. 2010.

SILVEIRA, Sheila Recepute; IDERIHA, Nilce Marzola. Uso de modelo tridimensional de argila no ensino-aprendizagem de embriologia humana. Mirabilia Medicinae, Barcelona, v. 1, p. 47-55, jul./dez. 2013.

SPRINGER, Kalina Salaib; NUMMER, Andrea Valli. O uso de massinha de modelar para compreensão do relevo representado nos mapas físicos: proposta de prática para a geografia escolar. In: SIMPÓSIO NACIONAL DE GEOMORFOLOGIA, 6., 2006, Goiânia. Anais... Goiânia: UFG, 2006. p. 1-9. 